\title{
Transformation of flood risk management with evolutionary resilience
}

\author{
HMM Herath $^{1, *}$ and NTS Wijesekera ${ }^{2}$ \\ ${ }^{1} \mathrm{PhD}$ candidate, Department of Civil Engineering, University of Moratuwa, Sri Lanka \\ ${ }^{2}$ NTS Wijesekera, Senior Professor, Department of Civil Engineering, University of Moratuwa, Sri Lanka
}

\begin{abstract}
The occurrence of flood disasters has become a vicious problem in many urban regions. Operationalization of flood resilience has become a significant concern with the increase of urban development and climate change. The objective of this paper is at first to analyze how flood resilience has been framed over the past period of time. Second, this paper has focused to identify the practical difficulties related to the available flood risk assessment and management frameworks for operationalization of flood resilience. The results show that the flood risk and resilience has been framed differently throughout the time, in diverse perspectives but still remains as contested concepts. Evolutionary resilience has been reframed the flood risk management system as an integrated and adaptive system with the recognition of the uncertainties due to the dynamics of socio-spatial interdependencies of flood risk. Therefore, the integration and the adaptive capacity of spatial planning has become a crucial aspect for operationalizing flood resilience which is governed through the knowledge base of the dominant discourses of stakeholders and the way of power and the resource exercised in the context.
\end{abstract}

Key word; Flood risk, assessment; Vulnerability; hazard; Uncertainty, resilience, spatial planning

\section{Introduction}

Worldwide, flooding is known as the most common of all-natural disasters that leads to great loss of life, risks to public health, damage to property, infrastructure and businesses and damage to ecosystems (Driessen, 2018.). Flooding becomes a disaster when an urban system significantly changes its functionality, structural identity, or feedbacks. Rapid increase of urban development and changes to climate has transformed the flooding as a significant risk to urban life. Uncertainty associated with urban flood risk due to socio economic factors has been found significant when compared with natural factors such as climate change (Klijn, 2012; Kok, 2016). Therefore, operationalization of flood resilience has become a significant concern with the increase of urban development and climate change.

\section{Objective and methodology}

The rationalist and constructivist paradigms provide perceptions for interpreting evidence and developing theory in flood risk (Kryžanowski, 2014)management (Birkholz, 2014). Flood risk management has been largely dominated by a rationalist thinking which has focused on understanding the physical processes associated with flood disaster occurrence. Constructivist perspective in flood risk challenges the rationalist thinking by highlighting the significance of social processes as intrinsic elements in disaster events. Accordingly, conceptualization of flood risk, assessment and management frameworks have advanced over the period of time with diverse perspectives. The evolution process can be broadly divided into three main phases mainly based on the conceptualization the dynamics of flood risk. Therefore, the objective of present work is to analyse the sequence of thinking in flood risk management to identify the practical difficulties related with the current flood risk management and to propose a way forward. The present work carried out a detailed review of material to capture the concepts and practices of flood risk management, there merits and short comings particularly consideration of uncertainty incorporated with flood risk.

The publications of the approximate period from 1950 -2019 were scrutinized for this evaluation. Results of the evaluations were utilized to systematically capture the practical issues and constraints that should be considered as the urgent requirements for operationalization of flood resilience. The present status and the identified gaps were then combined to identify the characteristics of best alternative options as frameworks for flood risk management.

\section{Probability of flood hazard}

$\overline{{ }^{*} \text { Corresponding author: malani@uom.lk }}$ 
In the very early days, the main concern of flood management was the probability of flood occurrence which focused on the physical phenomenon of flood as an entity independent of the social system. Decision making based on this assumes that the flood hazards in the future, can be predicted by rationally considering the occurrence of past floods. Accordingly, there are two main risk assessment processes under the probability-based risk assessment such as flood frequency assessment and expected annual damage assessment. The primary objective of flood frequency analysis is to relate the magnitude of extreme events to their frequency of occurrence through the use of probability distributions (Chow, 1988). Flood frequency method dealing with the prediction of river flow values corresponding to specific return periods, analysed the observed historical streamflow records to determine future probabilities of exceedance. In these assessments the parameters of flood events are considered as stationary and fixed and therefore, flood control structural measures had been designed assuming the stationary behaviour of hydrological system (Milly, 2008;Chow, 1988).

Later, estimation of probable damages has been considered as the core element of understanding the risk of flooding (Emanuelsson, 2014). Expected Annual Damage assessment considers the probability of flooding and the consequences as variables. The Expected Annual Damage (EAD) is calculated by integrating the damage exceedance probability curve utilizing the annual Exceedance Probability _ Loss (EPL) curves and the frequency-magnitude relationships (Aerts, 2013). Traditional flood controlling measures largely focused on keeping the water out of the landscape. Therefore, nonstructural flood control measures such as spatial planning did not play a role in flood risk management in the past. Initially, hydrologists were the principal contributors providing inputs for flood management decisions. Prior to 1970 's, their focus was more on controlling the flood losses by reducing the flood hazard by incorporating only flood control infrastructural measures (Kundzewicz, 2014.).Hence the traditional flood risk management solutions usually confined to the boundaries of watersystem aiming to address the probability of flooding suitable for a particular environment and associated infrastructure (Tempels, 2014). Water was considered as a technically controllable and adaptable element, largely subordinated to the creation of a built environment virtually anywhere.

\subsection{Early Period Drawbacks}

Inability to facilitate the estimation of total flood loss was considered as a major drawback in the probability-based damage assessments. Direct impacts of floods are associated with the immediate vicinity and the time of the flood event while the. indirect impacts are the consequences occurring beyond the actually flooded area, subsequent to flood event, and influencing effects on other sectors (Jonkman, 2008. ). Studies on this aspect had identified that indirect damage affects a wider area in both space and time.
Quantitative assessment of flood risk based on the flood frequency and expected annual damage are surrounded by considerable uncertainties (Merz, 2009). It has come to light that climate change affects the frequency and magnitude of floods and such changes modify the expected probabilities of flood occurrence and inundation. In the field of hydrology there is widespread recognition that most hydrologic processes exhibit nonstationary behaviour due to changes in land-uses, climate, and water infrastructure (Vogel, 2017). There had been the awareness that such changes to flood hydraulics are due to flood management interventions such as levees and land use controls. This brought the need of considering the uncertainties and risks associated with hydrologic and social systems into the limelight. Flood control designs in the past had paid no attention towards the interdependencies between land and water. The inability to manage the flood risk by controlling the hazard was recognized with this identification. Leveeeffect is a prime example showing the increase of flood damage potential as a result of a flood control infrastructure (Baldassarre G. D., 2013; Collenteur, 2015; de Bruijn, 2019; Liao,

2012; (Smits, Nienhuis, \& Saeijs, 2006). Direct handling of the dynamics of flood risk with simple statistical methods was blamed for the non-surfacing of associated uncertainties (Merz and Blöschl, 2008). However, the difficulties associated with applications amidst data deficiencies also would have caused problems when capturing damage in monetary terms.

\section{Flood hazard and vulnerability of physical and social systems}

The potential for flood damages has been considered due to floodplain development and properties on floodplains (Green, 1989). Accordingly, flood damage is a relationship between hazard and vulnerability (Wrachien, 2011). Vulnerability based risk assessment frameworks acknowledged that flood damage is largely caused by human decisions and associated actions. Thus, during 1980s, main focus of flood management models had been on vulnerability of the related social and physical factors. In general, vulnerability is the degree to which a system, subsystem, or a system component, experiences harm due to exposure to a hazard. After 1980s, most decision makers argued that natural disasters are socially constructed events and this resulted in reframing the conceptualization of flood risk. Along with this, the characteristics of social system was considered as responsible factors of vulnerability (Anderson, 1995). Hence, the magnitude of consequences was considered as an inherent characteristic of the receptor for which the value of harm is assigned by the affected society (Sayers, 2013). As a result, the importance of understanding the characteristics of flood exposure has been highlighted over the investigations in to the nature of hazard. The plural conceptualization of flood vulnerability has explained as follows. 


\subsection{Vulnerability of physical system}

Vulnerability encountered a mix of conceptualizations (Birkmann, 2006) and in the early 1980s, scholars theorized vulnerability as the characteristics of bio physical features of the elements subjected to exposure. Accordingly, flood vulnerability was primarily a function of the proximity to hazard (Brooks, 2003).In this conceptualization, physical characteristics of the exposure associated with the nature of hazard are taken as the firstorder impacts and these are either amplified or reduced by the biological and social characteristics of affected system (Brooks, 2003). Thus the presence at hazardous locations was regarded as the reason for stakeholder vulnerability (Cutter S. , 1996).

\subsection{Vulnerability of social system}

In the late 1980s, decision makers had considered that the social contexts such as societal resistance and resilience to hazards demonstrated by communities subjected to exposure are the main factors that contribute to vulnerability. In this the ability to cope with and to respond adequately to disasters are governed by historical, cultural, social and economic factors, and the processes that impinge the society. In the latter part of twentieth century, vulnerability had been described by considering the socio economic factors of the affected society (Cutter S. B., 2010). At the beginning of 1990s, decision makers had comprehended that flood vulnerability is depicted by biophysical characteristics and social response capacities of a particular locality (Cutter S. , 1996; Folke, 2002). Also it had been recognized that absolute flood prevention is unattainable. Therefore, the conceptualization of flood risk shifted towards managing the floods with a holistic perception (Scott, 2013; Schanze, 2006).

\subsection{Vulnerability of decision making systems}

At the Beginning of the $21^{\text {st }}$ century, vulnerability was considered as a broader focus within a humanenvironmental system. Vulnerability of flood prone population was considered as a complex phenomenon governed by multi-dimensional factors and processes that influence multiple scales and levels (Turner B.L., 2010). Decision makers recognized the flood vulnerability of social systems at any scale as a function of exposure, susceptibility to hazardous conditions and the resilience of the system (Carreño, 2005).The degree of vulnerability did not simply emerge from the interactions between external natural hazards and internal factors such as social inequality but also from the capacity of a system to manage threats (Naess, 2006). Flood vulnerability was considered as a characteristic involving the combination of social and hydrologic system rather than a property of social system alone (Gallopin, 2006). Therefore, resilience was considered as a counterpart of vulnerability, not as a means of coping with external changes or shocks but as a functionality which actively and positively respond to risks (Turner B.L., 2010). As a result, capacities of the flood control system were questioned with regards to coping the dynamics of risk associated socio spatial variables. It was recognized that not only the physical events but also the conditions of social system and its ability to plan and manage floodplains contributed to the transformation of a flood as a disaster. These circumstances gave rise to the need to consider potential interventions such as systematic planning of associated spatial extents.

However, the dynamics of social, ecological, hydrological system interactions, relations at multiple scales and levels are not explicitly described in the assessment and management frameworks of flood vulnerability (Yang, 2018). Moreover, they also lack sufficient explanations for the assessment of crossscale interactions (Birkmann, 2006). In most flood vulnerability-based decision-making frameworks, instead of making a clear distinction between the drivers, consequences and feedback loop systems for analytical assessments, a few readily available parameters are used to estimate the vulnerability value of a system (Balica, 2013). Further, it has been recognized shortcomings associated with the integration of socio economic development and spatial transformations in the flood vulnerability concepts. Therefore, vulnerability frameworks have created discussions on the integration of a holistic approach between the human and physical systems that are linked to floods (Fuchs, 2017)

\section{Hazard and resilience}

Since the latter part of 1990s, flood risk assessment began to question, the complexity of flood risk and the importance of resilience in the flood risk management Subsequently, the urban areas were conceived as human modified ecosystems comprising of complex social and ecological systems and processes which are consistently influenced at different levels, multiple scales and time frames. Further investigations revealed that these socioecological systems in urban areas consisted of sub systems such as resource and governance etc which are relatively separable but interact interdependently (Ostrom, 2009;Folke C. , 2016). Accordingly, urban systems were conceptualized not as neutral containers but as complex and interconnected socio-spatial systems, consisting of extensive and unpredictable feedback processes operating at multiple scales and time frames (Davoudi et al., 2012). The recognition of evolutionary resilience approach transformed flood risk management strategy from management of socio ecological issues towards development of robust socio-ecological systems. Accordingly, the traditional compartmentalized, equilibrium-based rationalist problem framing models of flood risk assessment and management were reshaped to become more adaptable, dynamic, and capable of handling non-equilibrium situations (Haasnoot, 2012).

Evolutionary resilience has been used as a promising flood risk management tool for analysing the stability of complex Socio Ecological Systems (SES) (Biggs, 2015). Evolutionary resilience explicitly emphasizes the importance of understanding the interactions of socio ecological systems, dynamics across temporal and spatial 
scales, their nonlinearities, tipping points and their evolving behaviours in order to maintain the stability of complex SESs. The inextricable link between water and land use activities which plays a major part in the concept of evolutionary resilience causes chains of impacts and responses that are intertwined and interactive (Pahl-Wostl C. D., 2005). Evolutionary resilience which recognizes the irreversible nature of SESs emphasizes the need to transform a system in response to stresses and pressures. As such, adaptability to change is the key focus of socialecological resilience when managing floods in complex and uncertain socio-ecological systems.

Accordingly, while using the already matured knowledge on hydrological uncertainty of floods, the decision making for flood risk management was coming to terms with the handling of the uncertainty associated with the socio-ecological system. A key factor being the recognition of importance to deal with the ontological assumptions that was linked with socio ecological system. The change in conceptualization is evident because of increased consideration of flood risk management in coherence with other land use functions such as housing, recreational, transport, nature conservation and heritage (Scott, 2013). This change has already commenced challenging the established physical and governance boundaries between land and water (Tempels, 2014). Moreover, flood risk management systems were identified as complex adaptive systems governed by nonlinear causalities, capable of coevolving with time and governed by the actions stakeholders. It was identified that the adaptive perspective of stakeholders alone would not be sufficient to implement flood resilience strategies. Although the capacity for transformation and selforganization is necessary, the degree of availability depends on the way resources and power are exercised in the governance system (Davoudi , 2012; White, 2014).

Therefore, assessment of adaptive capacity of decision-making process became a central challenge for the operationalization of flood resilience (Restemeyer, B., van den Brink, M., \& Woltjer, J., 2018). Deeper and slower variables of social systems such as identical values, core values, and worldviews of stakeholders and the flexibility of governance system are important aspects when assessing adaptability (Bennett, 2009).It is also necessary to assess the potential for widening of stakeholder roles and the potential for the generation of a common governance framework to balance the socio spatial dynamics of flood risk. The assessment of flood risk must lead to the definition of institutional arrangements, their dominant interactions, formal and informal rules, power and resource base of actors involved (De Bruijn, 2005;Hegger, 2014). Evolutionary resilience advocates a diversity of flood risk management measures, and the importance of adaptive and integrated modes of governance which can accept uncertainties. The options under this concept underlines different ways of organising land use over the flood plains by altering the natural processes and incorporating technical interventions to develop spatial quality, living patterns and social behaviours (Ferdous, 2018; Wardekker, 2010). Operationalisation objectives of the resilience based flood management involves the integration of land use demands of all stakeholders particularly, the spatial planners, flood managers, affected communities, etc., to achieve an improved spatial quality with better safety and higher environmental quality (Hooijer, 2004; Liao K.,2014). The main highlight of the operationalisation is to build adaptive capacity to reduce flood vulnerability by not destroying natural capital (Opperman, 2009).

Operationalisation of a flood resilient system comprises not only a physical setup but also the associated actors, their perceptions, legal frameworks, regulations etc. Hence this task becomes complicated because of the need to balance the desires of urban development while protecting floodplain functionality and character amidst the diverse governing arrangements under each social context (Hutter, 2007). Resilience based management systems requires flexibility that can offer a "soft landing" for the organization of stakeholders or the associated spatial structures. As a result, the requirement of governance tools which facilitate multiple stakeholders to reach shared solutions and to guide spatial transformation according to multiple trajectories have been emphasized for successful operationalization of flood resilience (Zandvoort, 2019). Role of spatial planning for flood resilience comes in to play because of the socio spatial dynamics associated with the management of flood risk (Woltjer and Al, 2007). Spatial planning which shapes the built environment across many spatial scales, supports the location of suitable land use types and their arrangement on flood plains. Therefore, spatial planning embedded with flood resilience concepts was recognized as a versatile tool for effective flood risk governance (Meng, 2019).

\section{Operationalization of flood resilience with spatial planning}

The current trend is to entrench spatial planning at national, regional, local and community level with the intention of influencing future distribution and pattern of activities in terms of their locations. Role of spatial planning systems has also been redefined as a process to improve policy integration, both vertically and horizontally, between actors and the scale of governance through spatial design (Albrechts, 2004). Flood damage estimation guidelines which are established worldwide and decisionmaking of flood risk is still dominated based on flood damage assessment methodologies. Quantifying of flood damage fails to capture the range of social, cultural, economic and institutional factors that shape the vulnerability of human populations to hazard events. Existing flood damage assessment guidelines rarely acknowledge uncertainty incorporated with flood risk. Many of the previous research studies are also focused on the hydrological component in which hydrologists focus their attention only on the management of hydrological system uncertainties. Recently, flood risk assessment guidelines have appreciated the assessment of flood risk in an integrated manner. In these guidelines consideration of multi-level, multi-sector and multi-actor governance for flood risk management has been brought to light. In 
these guidelines the assessment of uncertainty due to diverse framing of the flood risk and incorporation of actions by the decision makers, communities, and other stakeholders are yet to be considered in these guidelines. Moreover, the role of these guidelines should underline how to identify, quantify, evaluate and communicate the uncertainty associated with flood risk among stakeholders in spatial planning process.

The existing guidelines require to highlight the types, locations and the levels of uncertainty of flood risk in order to manage with spatial planning. A major factor which is missing in the presently available guidelines is the assessment of uncertainty while considering the key factors in the spatial planning process. This gap has been cited as a major cause for the insignificant role played by spatial planning towards sustainable management of flood risk (Ran, 2016) (Francesch-Huidobro, 2017).The present work revealed the lack of a commonly agreed framework and operational guidelines enabling easy practice of flood risk management incorporating the concept of resilience. This brings forth the need of more case studies to strengthen the flood risk management conceptualisation and assist the implementation with meaningful guidance. Therefore, case studies at various spatial scales and exposed to different mixtures of stakeholders are recommended to contribute towards operationalisation of sustainable flood risk management.

\section{Conclusions \& discussions}

Flood risk management efforts based on rationalistic approach have largely failed to arrest the underlying drivers of increased flood risk uncontrolled urbanization and proliferation of assets in hazardous areas. At the beginning of $2000 \mathrm{~s}$, the inadequate treatment of inherent uncertainties amidst high associated costs, categorized the rationalistic thinking as an ineffective measure. Passage of time increased the focus and understanding on the how and why of disaster damage, the type of those affected and the nature of potential strategies, measures and interventions etc to achieve better management and mitigation of flood impacts. These efforts rapidly moved towards greater appreciation and accounting of human dimension in flood disaster management.

Constructivist thinking commenced advocating a comprehensive exploration of socio-cultural context that influences the influences the outcomes of disastrous events to bring about social and environmental injustice. Accordingly, stakeholder vulnerability became a key factor of flood risk management However, the diversity in the interpretation of vulnerability resulted in new flood risk management decision making framework. Gradually, the decision making associated with flood management recognized the role of stakeholder resilience as a key factor which captures the ability of society to pursue its social, ecological and economic development objectives. Accordingly, cotemporary flood risk management research has embraced the constructivists perspective, which claims to mutually reinforce the development objectives of society and management of flood disasters. Therefore, this paper concludes that there are inadequacies in the conceptualization and operationalization of stakeholder resilience in relation to flood risk management. Therefore, it is important to understand the inadequacy of existing flood risk assessment and management frameworks for operationalization of flood resilience.

Operationalization of flood risk management requires a situation analysis to capture the flood risk, then design a suitable spatial planning strategy to reduce the flood hazard and finally incorporate an appropriate governance system to implement the changes to the existing spatial structure. Selection of alternatives must consider the appropriateness of design floods, the terrain and spatial distribution of floods, damage assessments and the resilience of stakeholders. Hence it is necessary to design the governance system to implement diversified flood management strategies by navigating the expected change of spatial structure with a careful consideration of dominance and distribution of resources in the flood system. This means that the governance framework need to support negotiation of stakeholder aspirations to negotiating the aspirations of stakeholders to lean towards implementation of risk-based flood management strategies. The present work revealed the lack of a commonly agreed framework and operational guidelines enabling easy practice of flood risk management incorporating the concept of resilience. This brings forth the need of more case studies to strengthen the flood risk management conceptualization and assist the implementation with meaningful guidance. Therefore, case studies at various spatial scales and exposed to different mixtures of stakeholders are recommended to contribute towards operationalization of sustainable flood risk management.

Authors greatly acknowledge the Research \& publication grant of University of Moratuwa, Sri Lanka.

\section{References}

1. Anderson, M. (1995). Vulnerability to disaster and sustainable development: A general framework for assessing vulnerability. Disaster Prevention for Sustainable Development: Economic and Policy Issues. . Washington, DC:: World Bank,.

2. Balica, S. P. (2013). Balica, S.F., Popescu, I., Beevers, L. and Wrig Parametric and physically based modelling techniques for flood risk and vulnerability assessment: a comparison. . Balica, S.F., Popescu, I., Beevers, L. and Wright, N.G., 2013. Parametric and physically based modelling techniqu Environmental modelling \& software, Balica, S.F., Popescu, I., Beevers, L. and Wright, N.G., 2013. Parametric and physically based modelling techniques fo pp.84-92.

3. Bennett, E. P. ( 2009). Bennett, E.M., Peterson, G.D. and $\mathrm{G}$ Understanding relationships among multiple ecosystem service. Ecology letters, 12(12), pp.13941404 . 
4. Biggs, R. S. (2015). Principles for building resilience: sustaining ecosystem services in socialecological systems. . Cambridge University Press.

5. Birkmann, J. (2006). Measuring vulnerability to promote disaster-resilient societies: Conceptual frameworks and definitions. Measuring vulnerability to natural hazards: Towards disaster resilient societies. Birkmann, J., 2006. Measuring vulnerability to promote disaster-resilient societies: Conceptual frameworks a Towards disaster resilient societies, 1, Birkmann, J., 2006. Measuring vulnerability to promote disaster-resilient societies: Conceptual frameworks and dpp.9-54.

6. Brooks, N. 2.-1. (2003). Brooks, N., 2003. Vulnerability, risk and adaptation: A conceptual framework. Tyndall Centre for Climate Change Research Working Paper, 38(38), pp.1-16. Brooks, N., 2003. Vulnerability, risk and adaptation: A conceptual framework. Tyndall Centre for Climate Change Research Working Paper, 38(38), pp.1-16, pp.1-16.

7. Carreño, M. C. (2005). Evaluation of the risk management performance. . Carreño, M.L., Cardona,

8. O.D. and Barbat, A.H., 2005. Evaluation of the risk management performance. In Proceedings of the International Conference: 250th Anniversary of the 1755 Lisbon earthquake.

9. Chow, T. M. (1988). Applied Hydrology. . New York: McGraw-Hill,

10. Cutter, S. (1996). Vulnerability to environmental hazards. Progress in human geography, 20(4), pp.529-539.

11. Cutter, S. B. (2010). Disaster resilience indicators for benchmarking baseline conditions. Journal of Homeland Security and Emergency Management, $7(1)$.

12. Driessen, P. H. (2018.). Driessen, P., Hegger, D., Kundzewicz, Z., van Rijswick, H., Crabbé, A., Larrue, C., ... \& Raa Governance strategies for improving flood resilience in the face of climate change. . Driessen, P., Hegger, D., Kundzewicz, Z., van Rijswick, H., Crabbé, A., Larrue, C., ... \& Raadgever, G. (2018). Water,., Driessen, P., Hegger, D., Kundzewicz, Z., van Rijswick, H., Crabbé, A., Larrue, C., ... \& Raadgever, G. (2018). G10(11), 1595.

13. Emanuelsson, M. A. (2014). Flood risk assessment for infrastructure networks. Journal of Flood Risk Management, , 7(1), 31-41.

14. Francesch-Huidobro, M. D. (2017). FranceschHuidobro, M., Dabrowski, M., Tai, Y., Chan,

15. F.Governance challenges of flood-prone delta cities: Integrating flood risk management and climate change in spatial planning. . Progress in Planning, 114, pp.1-27.

16. Fuchs, S. K. ( 2017). Fuchs, S., Karagiorgos, K., Kitikidou, K., Maris, F., Paparrizos, S. Flood risk perception and adaptation capacity: A contribution to the socio-hydrology debate. Hydrology and Earth
System Sciences, 21(6), Fuchs, S., Karagiorgos, K., Kitikidou, K., Maris, F., Paparrizos, S. and Thaler, T., 2017. Flood risk perception and adaptation capacity: A copp.3183-3198.

17. Gallopin, G. (2006). Linkages between vulnerability, resilience and adaptive capacity. Global Environmental Change 16 (3), 293-303.

18. Green, C. a. - R. (1989). Flooding and the quantification of 'intangibles'. Water and Environment Journal, 3(1), pp.27-30.

19. Haasnoot, M. a. (2012). Haasnoot, M. and Midde A history of futures: a review of scenario use in water policy studies in the Netherlands. Environmental science \& policy, 19, pp.108-120.

20. Hutter, G. (2007). Strategic planning for long-term flood risk management: some suggestions for learning how to make strategy at region. International Planning Studies, 12(3), pp.273-289.

21. Jonkman, S. a. (2008. ). Loss of life due to floods. . Journal of Flood Risk Management, 1(1), , pp.4356.

22. Kryžanowski, A. B. (2014). . Structural floodprotection measures referring to several European case studies. . Natural hazards and earth system sciences, 14(1), , pp.135-142.

23. Kundzewicz, Z. K.-W. ( 2014.). Flood risk and climate change: global and regional perspectives. Hydrological Sciences Journal, 59(1), pp.1-28.

24. Merz, B. E. (2009). Significance of" high probability/low damage" versus" low probability/high damage" flood events. Natural Hazards and Earth System Sciences, 9(3), pp.10331046., pp.1033-1046.

25. Naess, L. N. (2006). Data and processes linking vulnerability assessment to adaptation decisionmaking on climate change in Norway. . Naess, L.O., Norland, I.T., Lafferty, W.M. and Aall, C., 2006. Data and processes linking vulnerability assessment to aGlobal Environmental Change, 16(2), pp.221-233.

26. Opperman, J. G. (2009). Opperman, J.J., Galloway, G.E., Fargione, J., Mount, J.F., Richter,

27. Sustainable floodplains through large-scale reconnection to rivers. Opperman, J.J., Galloway, G.E., Fargione, J., Mount, J.F., Richter, B.D. and Secchi, S., 20Science, 326(5959), pp.1487148.

28. Pahl-Wostl, C. D. (2005). Transition to adaptive water management: the NeWater Project.

29. Ran, J. a.-B. (2016). Ran, J. and N Integrating spatial planning and flood risk management: A new conceptual framework for the spatially integrated policy infrastructure. . Ran, J. and NedovicBudic, Z., 2016. Integrating spatial planning and flood risk management: A new conceptual framework Computers Environment and Urban Systems, 57, Ran, J. and Nedovic-Budic, Z., 2016. Integrating spatial planning and flood risk management: A new conceptual framework for the pp.68-79. 
30. Restemeyer, B., van den Brink, M., \& Woltjer, J. (2018). Restemeyer, B., van den Brink, M., \& Resilience unpacked-framing of 'uncertainty'and 'adaptability'in long-term flood risk management strategies for London and Rotterdam. Restemeyer, B., van den Brink, M., \& Woltjer, J. (2018). Resilience unpacked-framing of 'uncertainty'and 'adaptability'in longterm floodEuropean planning studies, Restemeyer, B., van den Brink, M., \& Woltjer, J. (2018). Resilience unpacked-framing of 'uncertainty'and 'adaptability'in long-term flood 26(8), 1559-1579.

31. Sayers, Y. L.-R. (2013). Flood Risk Management: A Strategic Approach. . Paris, : UNESCO.

32. Scott. (2013). Living with flood risk/The more we know, the more we know we don't know:. Planning Theory \& Practice 14, no. 1, 103-140.

33. Smits, A., Nienhuis, P., \& Saeijs, H. ( 2006). Changing estuaries, changing views. . Hydrobiologia, 339-355.

34. Tempels, B. a. (2014). A co-evolving frontier between land and water: dilemmas of flexibility versus robustness in flood risk management. Water international, 39(6), pp.872-883.

35. Turner B.L. (2010). Vulnerability and resilience: Coalescing or paralleling approaches for sustainability science? Global Environmental Change, pp.570-576.

36. Wrachien, D. M. (2011). Wrachien, D., Mambretti, S. and Flood management and risk assessment in flood. prone areas: Measures and solutions. Irrigation and Drainage, 60(2), pp.229-240.

37. Yang, J. Z. (2018). Yang, J., Zhou, M., Li, M., Liu, X., Yin, P., Sun, Q., Wang, J., Wu, H.,

38. Wang,Vulnerability to the impact of temperature variability on mortality in 31 major Chinese cities. Yang, J., Zhou, M., Li, M., Liu, X., Yin, P., Sun, Q., Wang, J., Wu, H., Wang, B. and Liu, Q., 2018. Vulnerability to the impaEnvironmental Pollution, pp.631-637.

39. Zandvoort, M. v. (2019). ZZandvoort, M., van der Brugge, R., van der Vlist, M. J., \& van den Brink, Dealing with uncertainty in collaborative planning: developing adaptive strategies for the IJsselmeer. Zandvoort, M., van der Brugge, R., van der Vlist, M. J., \& van den Brink, A.

40. (2019). Dealing with uncertainty in collaborative planning: developing adaJournal of

41. Environmental Planning and Management, Zandvoort, M., van der Brugge, R., van der Vlist, M. J., \& van den Brink, A. (2019). Dealing with uncertainty in collaborative planning:

42. developin 62(2), 248-265. 